\title{
Pericardial effusion in a pediatric patient with influenza A H3N2
}

\author{
Derrame pericárdico en paciente pediátrico con influenza A H3N2 \\ Carlos E. Vergara-Uzcategui*, Édgar López-Rondón, and Robinson Cabrera \\ Cardiology Unit, Hospital Provincial General Pablo Arturo Suárez, Quito, Ecuador
}

\section{Case presentation}

Influenza is an acute viral infection whose clinical presentation is characterized by fever and symptoms such as headache, lethargy, and myalgia. Very rarely it has clinical sequelae ${ }^{1}$. The Influenza A virus, may lead to pulmonary, neurological, renal, musculoskeletal, and cardiac complications, including as myocarditis and pericarditis ${ }^{2}$.

The patient in question was a twenty month-old male patient, born at 38 weeks of gestation, after an uncomplicated pregnancy. At birth it was noted that he had typical features of Down's syndrome. Genetic testing confirmed this at two months. He was admitted to the emergency department with a seventy-two hour history of fevers, productive cough, tachypnea and lethargy, without improvement. On physical exam, he was noted to be irritable and pale. His weight was $7 \mathrm{~kg}$, his heart rate was $111 \mathrm{bpm}$ with a respiratory rate of 50 . His axillary temperature $35.3^{\circ} \mathrm{C}$, with a blood pressure of $93 / 62 \mathrm{mmHg}$. His jugular vein was not raised. On further inspection, the thorax was symmetrical with mild subcostal retractions noted. On auscultation scarce bilateral basal rales of the right predominance and muffled heart sounds were noted. No murmers were noted. The laboratory examinations including a full blood count, revealed a hypo-chromic, microcytic anemia and that the thyroid function was within normal limits. An arterial blood gas sample confirmed the presence of respiratory alkalosis. Thyroid function tests were

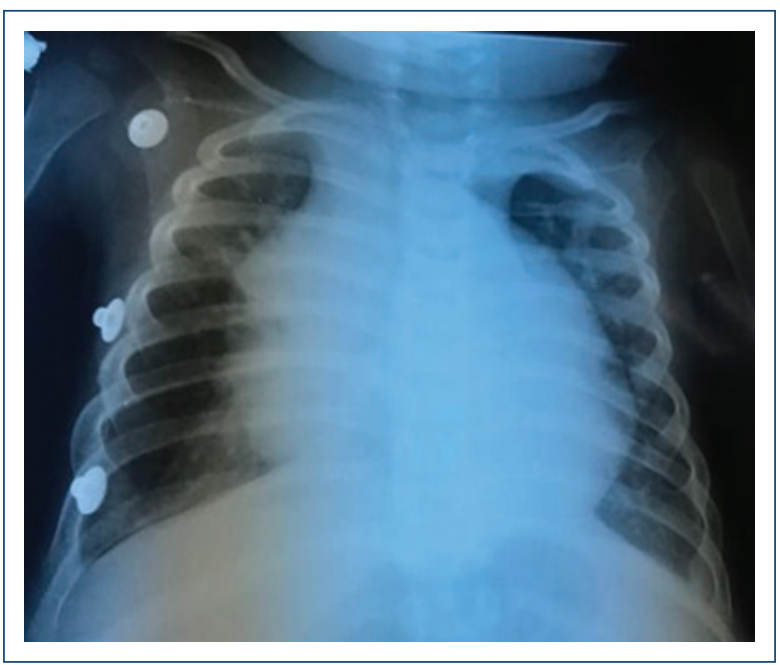

Figure 1. Chest X-ray. Anteroposterior projection, with arches horizontalization, free costophrenic and cardiophrenic angles, rounded heart silhouette, and increased in size. Interstitial pattern with no bronchopneumonic focus.

normal. A chest X-ray exhibited cardiomegaly (Fig. 1). Transthoracic echocardiogram showed moderate pericardial effusion (12 $\mathrm{mm}$ measured at the left ventricle [LV] posterior wall), without echocardiographic signs of tamponade, preserved biventricular systolic function, patent ductus arteriosus (PDA) with the left-to-right short circuit, moderate pulmonary regurgitation, and mild tricuspid regurgitation with pulmonary artery systolic pressure of $53 \mathrm{mmHg}$ (Fig. 2). A nasopharyngeal

\section{Correspondence:}

${ }^{*}$ Carlos E. Vergara-Uzcategui

E-mail: carting1 @ gmail.com
Available online: $12-03-2020$ Arch Cardiol Mex (Eng). 2019;89(4):380-382 www.archivoscardiologia.com 2604-7063/@ 2019 Instituto Nacional de Cardiología Ignacio Chávez. Published by Permanyer. This is an open access article under the CC BY-NC-ND license (http://creativecommons.org/licenses/by-nc-nd/4.0/). 

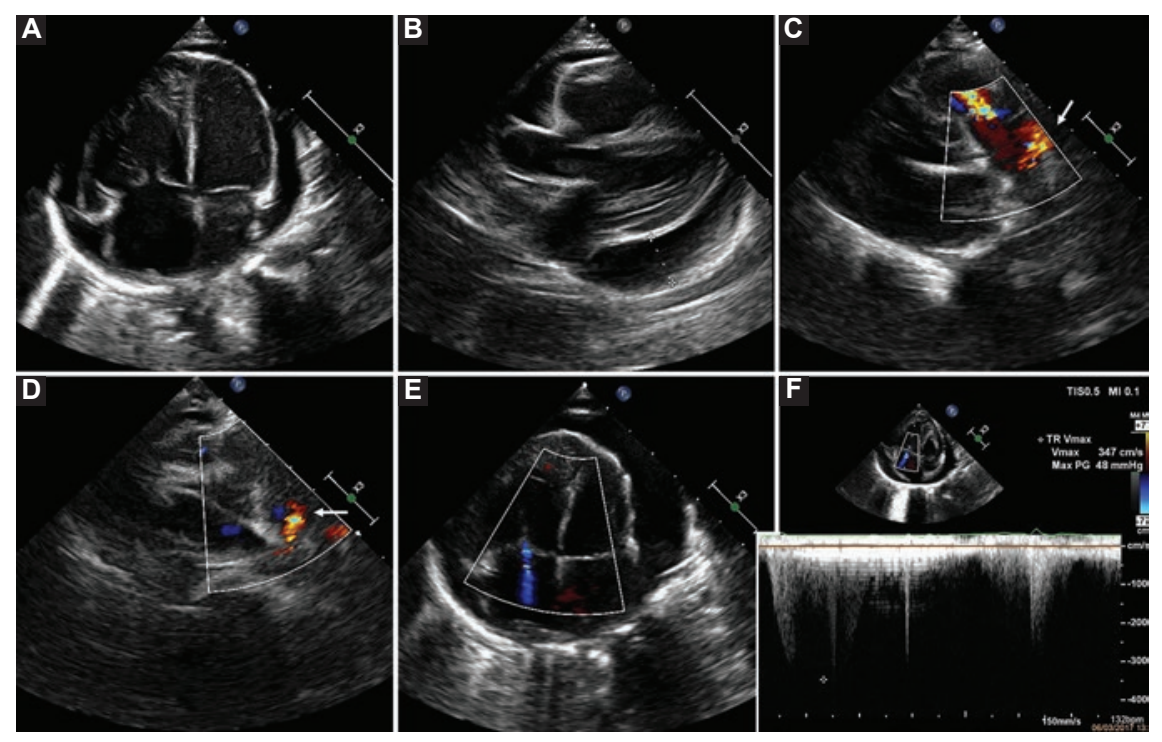

Figure 2. Echocardiogram. A: four-chamber apical view, where circumferential pericardial effusion is observed, without cavity collapse during diastole; right cavities dilation. B: Iong parasternal axis; pericardial effusion is measured in the left ventricle posterior wall $(15 \mathrm{~mm})$. C and D: large vessels short parasternal axis, modified; patent ductus arteriosusoriginating flow toward the pulmonary artery (arrows) and regurgitation jet in the pulmonary valve are observed with color Doppler. E: four-chamber apical view, with color Doppler on tricuspid valve; mild tricuspid regurgitation is shown. F: assessment with continuous Doppler on tricuspid regurgitation that registers a $48 \mathrm{mmHg}$ gradient.

swab was positive for influenza H3N2 subtype. Pharmacological therapy was commenced and oseltamivir $30 \mathrm{mg}$ was administered twice daily in conjunction with acetaminophen $96 \mathrm{mg}$ every eight hours. Follow-up echocardiography at the time of clinical resolution confirmed the pericardial effusion had resolved.

Influenza A is divided into 16 hemagglutinin subtypes ( $\mathrm{H} 1$ to $\mathrm{H} 16)$ and nine neuraminidases (N1 to N9) ${ }^{3}$. Myopericarditis is a rare but potentially lethal complication. Obese patients, pregnant women, children under the age of five, and immunosuppressed patients have a considerable risk of complications or death ${ }^{2}$. Electrocardiographic abnormalities, cardiac enzymes elevation, and LV contractility abnormalities have been reported, which can present with or without accompanying clinical symptoms ${ }^{4}$.

Rarely is myocyte damage accompanied by direct virus cytolytic effects, which plays an important role in cases of early myocardial damage ${ }^{2}$. TNF $\alpha$ plays an importanct role in the development of inflammatory cardiomyopathies. Previous reports have described that Influenza A accosicated myocarditis is releated to the expression of TNF $\alpha$ and its myocardial receptors. Influenza $A$ associated myocarditis typically presents during the first week of symptom onset. It is thought this is as a direct result of the virus itself or by an immune mediated inflammatory response'.

The Influenza A H1N1 virus, and in this case the H3N2 strain, are rarely associated with pericardial effusion, as was the case with this patient ${ }^{3}$. Infrequently, this may lead to cardiac tamponade.

Viral myocarditis can be caused by a wide variety of viral infections, most notably enterovirus, adenovirus, parvovirus, cytomegalovirus, and influenza virus ${ }^{2}$.

To definitively diagnose viral pericarditis, one should consider histological, cytological, immunohistolochemistry, pericardial fluid and both pericardial and epicardial biopsy molecular investigations. Whilst these investigations are desired to definitively confirm this diagnosis, they are not routinely performed in clinical practice ${ }^{6}$. In this case, a viral cause was confirmed with nasopharyngeal swab, which has sensitivity of $66-100 \%$.

Tipically, acute viral pericarditis is self-limiting and responds well to the administration of concomitant short course of non steroidal drugs and cochicine. These drugs are especially useful in the prevention of recurrent presentations. Corticosteroids are not indicated in viral pericarditis, as they can exacerbate viral infections prolong the inflammation ${ }^{5}$. Previous case reports have outlined the requirement for invasive supportive treatment including the need for extracorporeal membrane oxygenation ${ }^{7}$ 
in certain severe clinical presentations ${ }^{7}$. Pericardiocentesis was not performed in this patient as he had no clinical or echocardiographic signs of tamponade.

Down syndrome has an approximate incidence of $1 / 750$ births. This genetic anomaly is characterized by intrinsic immune deregulation and both decreased intrinsic and acquired immune response secondary to premature aging of the immune system. There can also be respiratory tract nomalies that may predispose the patient to chronic infections ${ }^{8}$. In addition, hypothyroisim may be masked due to overlapping clinical characteristics accompanying Down's syndrome ${ }^{8}$. In this case, thyroid function was found to be within normal limits. Trisomy 21 is also fequently associated with atrial septal defect, ventricular septal, PDA, and atrioventricular canal defect, among others. These congenital heart defects may be associated with clinical or subclinical pulmonary hypertension and pericardial effusions. However, in this patient, pericardial effusion remission was was confirmed at the time of clinical resolution and was therefore not as a result of the presence of pulmonary hypertension or PDA.

\section{Funding}

This research has not received any specific grant from public or commercial sector agencies or non-profit entities.

\section{Conflicts of interest}

The authors declare that they have no conflicts of interest.

\section{Ethical disclosures}

Protection of people and animal subjects. The authors declare that no experiments were performed on humans or animals for this study.

Confidentiality of data. The authors declare that they have followed the protocols of their work center on the publication of patient data.

Right to privacy and informed consent. The authors have obtained written informed consent of the patients and/or subjects mentioned in the article. The corresponding author is in possession of this document.

\section{References}

1. Tseng GS, Hsieh CY, Hsu CT. Myopericarditis and exertional rhabdomyolysis following an influenza A (H3N2) infection. BMC Infect. Dis. 2013;13:283-6.

2. Lefeuvre $\mathrm{C}$, Behillil S, Triau S. Fatal myopericarditis following an influenza A (H3N2) infection. Am J Case Rep. 2018;19:540-4.

3. Sidhu RS, Sharma A, Paterson ID. Influenza H1N1 infection leading to cardiac tamponade in a previously healthy patient: a case report. Res Cardiovasc Med. 2016;5:e31546.

4. Ito T, Akamatsu K, Ukimura A. The prevalence and findings of subclinical influenza-associated cardiac abnormalities among japanese patients. Intern Med. 2018;57:1819-26.

5. Adler Y, Charron P, Imazio M Badano L, Barón-Esquivias G, Bogaert J, et al. ESC Scientific Document Group; 2015 ESC Guidelines for the diagnosis and management of pericardial diseases: The Task Force for the Diagnosis and Management of Pericardial Diseases of the European Society of Cardiology (ESC). Eur Heart J. 2015;36:2921-64.

6. Vakamudi S, Ho N, Cremer PC. Pericardial effusions: causes, diagnosis, and management. Prog Cardiovasc Dis. 2017;59:380-8.

7. Hékimian $G$, Jovanovic $T$, Bréchot $N$, Lebreton $G$, Leprince $P$, Trouillet $\mathrm{JL}$, et al. When the heart gets the flu, Fulminant influenza $\mathrm{B}$ myocarditis: a case-series report and review of the literature. J Crit Care. 2018;47:61-4.

8. Avilés-Martínez KI, Pintor-Márquez GT, Meza-Jáuregui AL, Magaña-Cárdenas MT, Jasso-Estiven J, Mesino-Armenta T, et al. Neumonía y derrame pericárdico en pacientes pediátricos con síndrome Down e hipotiroidismo: reporte de cuatro casos atendidos en el departamento de urgencias. Rev Med MD. 2011;3:6-9. 